\title{
Regional Research of Classroom Needs in Secondary Schools in Turkey-2013
}

\author{
Nazli Gökçe ${ }^{1}$, Erdoğan Kaya ${ }^{2}$, Semra Günay Aktaş ${ }^{3}$ and Yeliz Mert Kantar ${ }^{4}$ \\ ${ }^{1,2}$ Faculty of Education, Anadolu University, Eskisehir 26470, Turkey \\ ${ }^{3}$ Faculty of Tourism, Anadolu University, Eskisehir 26470, Turkey \\ ${ }^{4}$ Department of Statistics, Anadolu University, Eskisehir 26470, Turkey
}

Correspondence should be addressed to: Yeliz Mert Kantar; ymert@anadolu.edu.tr

Received date: 2 December 2016; Accepted date: 6 June 2017; Published date: 4 December 2017

Academic Editor: Nehemiah Mavetera

Copyright (C 2017. Nazli Gökçe, Erdoğan Kaya, Semra Günay Aktaş and Yeliz Mert Kantar.Distributed under Creative Commons CC-BY 4.0

\begin{abstract}
The fact that the number of students in a class is high is one of the main factors that negatively affect the quality of education. It is well-known that a change in the education system in Turkey 2013, where schools were divided into primary, secondary, and high schools in accordance with gradient educational plan $(4+4+4)$, has increased the number of students per class. Therefore, the distribution of the number of students per class in rural and urban secondary schools in Turkey in 2013 has been investigated in this study, and the main efforts have been directed to determine classroom needs regionally. For this purpose, statistical data were obtained from the Turkish Institute of Statistics and the Ministry of National Education. Mapping analyses and local Moran's I analyses have been applied to specify classroom needs of secondary schools for urban and rural areas. Additionally, local cluster maps have been used to analyze the data spatially in order to further interpret the degree for clustering of similar data. Results of analyses show that the distribution of the number of students per class in rural secondary schools is not balanced in Turkey. Also, rural secondary schools in the east and southeast of Turkey are in need of classrooms. For urban regions, no global clusters have been detected, and attention should be drawn on only metropolitan cities. Moreover, these results have been supported by local spatial analysis.
\end{abstract}

Keywords: Turkey; Secondary school; Classroom need; Student; Mapping analyses; Spatial clustering.

\section{Introduction}

In Turkey, which is a developing country, a relatively high degree of multidimensional inequality is prevalent due to limited resources. As an important factor in economic growth and development, education is an increasing concern. On the

Cite this Article as: Nazli Gökçe, Erdoğan Kaya, Semra Günay Aktaş and Yeliz Mert Kantar (2017)," Regional Research of Classroom Needs in Secondary Schools in Turkey-2013", Journal of Enterprise Resource Planning Studies, Vol. 2017 (2017), Article ID 661323, DOI: 10.5171/2017.661323 
other hand, there is a close relationship between the educational and developmental levels of countries. Unlike other countries, the concepts of basic education and primary education in Turkey have been used interchangeably for many years. In elementary education, secondary school forms an important part of basic education in Turkey. Moreover, secondary school is also an important step since students make their professional choices during these years. Various legal regulations were enacted about the educational system in Twentieth-Century Turkey. Eight-year elementary education became mandatory according to the last regulation legislated in 2012. Thus, schools were divided into primary, secondary, and high schools in accordance with gradient educational plan $(4+4+4)$, although this change led to problems concerning school capacities.

A main indicator of the physical capacities of schools is the number of students per class (Gokce et al, 2016; Gokce et al. 2017). It is claimed that the distribution of students per classroom is not equal in Turkey. On the other hand, the optimum number of students per class has been discussed in numerous studies (Akkalkan, 2009; Karakutuk and Tunc, 2004); yet, it is still an on-going problem in Turkey. Many research studies have clearly explained that the number of students per class is excessively high in Turkey (Aydin et al. 2012; Cingi et al., 2008; Gokce et al. 2017).

Taking the studies into account, it is seen that class size or population of class is influential over students' success and development of skills. Furthermore, a small classroom size and also crowded classes obstruct students' participation to the lesson, their interaction with the teacher, and also teachers' classroom management.

Experts claim that students in crowded classes take less responsibility than the ones in uncrowded classes. They also claim that there should be a balance in terms of classroom population, and that 30 and more than 30 can be accepted as crowded while 17 to 20 is the ideal population size (Finn, et al. 2003, p. 351). It is seen from studies that the quality of education decreases as population of classrooms gets bigger. Moreover, overpopulated classes obstruct teachers to fulfill their functions in class (Ogulmus and Ozdemir, 1995).

Some research has concluded that the ideal number of students in a classroom is between 20 to 30 , and any class containing more than 30 students should be considered over-populated (Basar, 1999; Baytekin, 2001; Finn at al., 2003; Finn, 2002 cited in Guclu, 2002; Isik, 2012; Karacali, 2006; Onder et al. 2013; Yaman, 2006). In this study, spatial distributions of the number of students per class in secondary schools in provinces of Turkey has been examined. In this context, analyzing the number of students per class in secondary schools is useful in describing the present situation and developing future plans for the education system of Turkey.

Nowadays, spatial statistics tools have been used in studying social science data with geographical features. They help to identify spatial patterns and spatial distribution of the considered factor or variable effectively. The purpose of the study is to show a spatial distribution of the number of students per class in secondary schools in Turkey, and hopefully to reveal the need for classrooms in secondary school.

The study has sought answers to the following questions in accordance with the main purpose:

- What is the distribution of students per class in rural and urban secondary schools in Turkey?

- What is the distribution of classroom need across rural and urban secondary schools in Turkey?

- Is there any spatial clustering of distribution of students per class and classroom need in rural and urban secondary schools in Turkey? 
Method

\section{Data Source}

Research data in this study were taken from the Ministry of National Education (MNE) and Turkish Statistical Institute (TSI).

\section{Analyses \\ Maps for the number of students per class}

The data concerning the number of students per class in secondary schools has been mapped for 2013. The spatial distribution of the number of students per class is separately studied for rural and urban areas. In all the maps, light color points to underpopulated classes while dark color shows over-populated classes.

\section{Maps for the classroom need}

Lastly, the maps for classroom needs are sketched to see the available distribution of classrooms in rural and urban secondary schools. A total of 25 students, quite common and very well acceptable for class population, is used as the criterion for classroom needs. Ideal number of classrooms is calculated as follows: Adequate Number of Classrooms = Number of Students / 25. Then, this number was subtracted from the present number of classrooms, and how many classrooms were needed or how many were extra was determined (The Number of Classrooms Needed $=$ The Number of Present Classrooms- Adequate number of Classrooms). In all the maps, light color points to an extra number of classrooms while dark shows excessive number of classroom needs.

\section{Spatial Clustering}

Spatial analysis is a quantitative method used for the analysis of spatial distributions and spatial similarities, as well as spatial correlations or spatial dependence based on the context of the study. The map obtained from Local Moran's I values shows spatial clustering. In the map, HighHigh (HH) and Low-Low (LL) values indicate spatial clustering of similar values of the variable, which indicates the fact that the observed value is similar to its neighbors. Both $\mathrm{H}-\mathrm{H}$ means that high values are surrounded by high value neighbors, while LL indicates that low values are surrounded by low value neighbors. On the other hand, locations with Low-High values (LH) and High-Low values (HL) demonstrate potential spatial outliers, which means that high values are surrounded by low value neighbors, while a low value is surrounded by high value neighbors.

\section{Findings}

The Spatial Distribution of the Number of Students per Class in Secondary Schools in Rural and Urban Areas

As can be seen in Map 1, Figure 1 showing secondary schools in rural areas, the number of students per class is very high in Turkey's Southeast and East regions, and also in some parts of Central Anatolia region such as Ankara, Yozgat, Kayseri, and Konya. Also, Adana, a metropolitan city, Mugla, which is a popular-seaside city, and Tekirdag have a problem concerning overpopulated classes. In the southeast of Turkey, Sirnak does not have a serious problem as expected. The map clearly shows that the distribution of the number of students per class in rural secondary schools is not balanced in Turkey. 


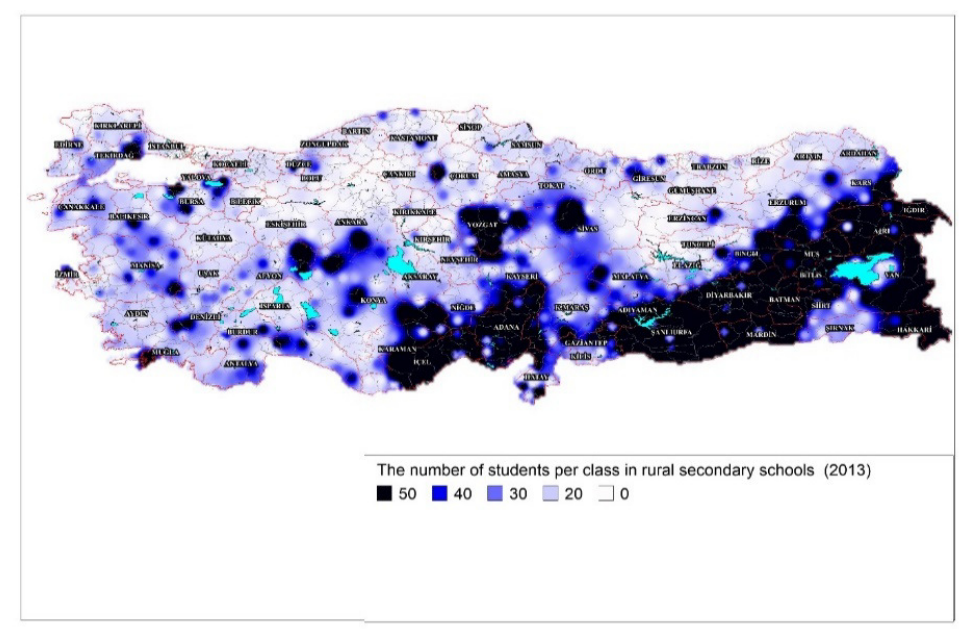

Figure 1: The distribution of the number of students per class in rural

\section{secondary schools (2013)}

Figure 2 shows the distribution of the number of students per classroom in urban secondary schools in Turkey. From this figure, it is seen that the number of students per class is high throughout the whole country. It is also notable that the number of students per class in secondary schools is quite high for metropolitan areas such as Istanbul, Bursa, Manisa, Izmir, Antalya, Mersin, Ankara, Eskisehir, Samsun, and Erzurum. On the other hand, there are crowded classes in the small provinces in Central Anatolia. Similar to the rural case, the number of students per class in urban areas is very high in Turkey's south, southeast and east regions. Also, similar to rural cases, Sirnak does not have a major problem concerning over-populated classes.

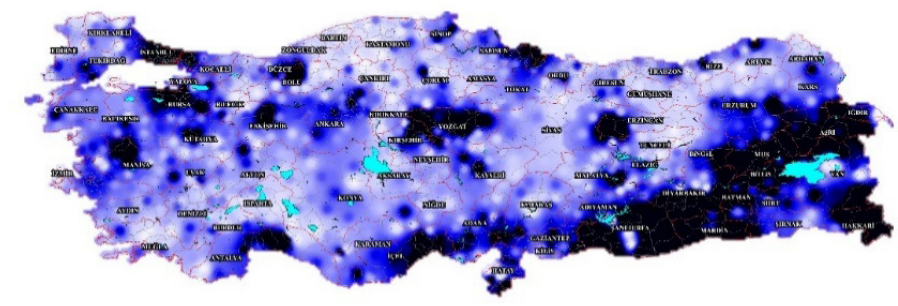

The number of students per class in urban secondary schools (2013) - $50 \quad{ }_{40} \quad{ }_{30} \quad{ }_{20} \quad{ }_{20}$ 
The Spatial Distribution of Classroom Need across Secondary Schools within Rural and Urban Areas
Also, classroom need in rural and urban areas is analyzed by means of maps accompanied by relevant interpretations.
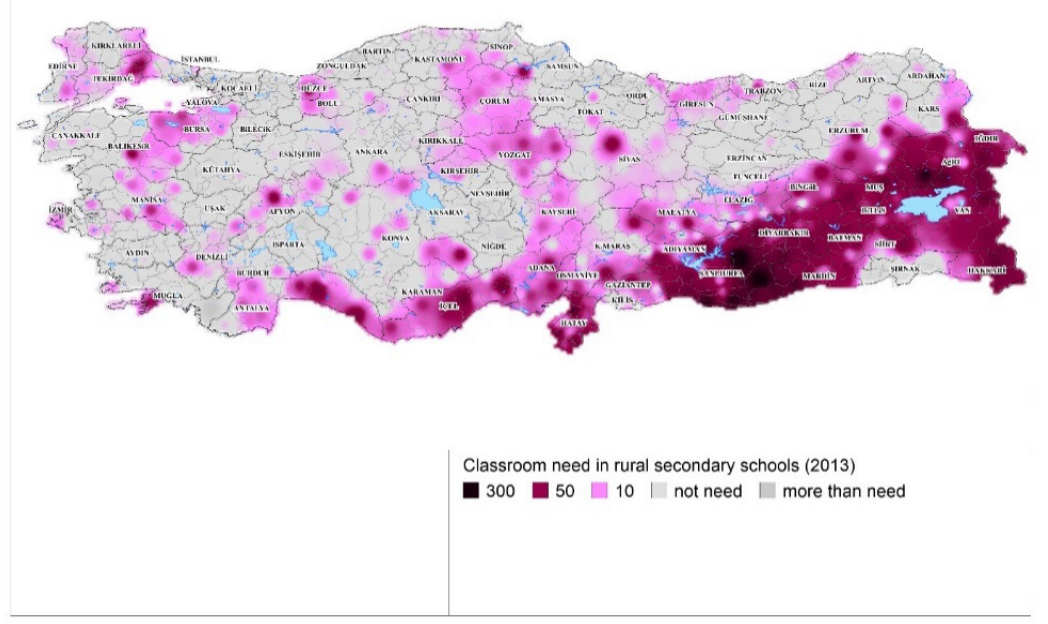

Figure 3: The distribution of classroom need across rural secondary schools (2013)

Figure 3 provides the distribution of classroom need across rural secondary schools in Turkey. As can be seen from Figure 3, classroom need is not serious for most of the regions in Turkey except for South, Southeast, and East regions. Even, the number of classrooms in some rural secondary schools is more than necessary.
Thus, it can be said that rural secondary schools with highly insufficient number of classrooms are spread throughout all regions. Particularly, Southeast region, except for Sirnak, should have priority in terms of eliminating the problems regarding classroom need for secondary schools.
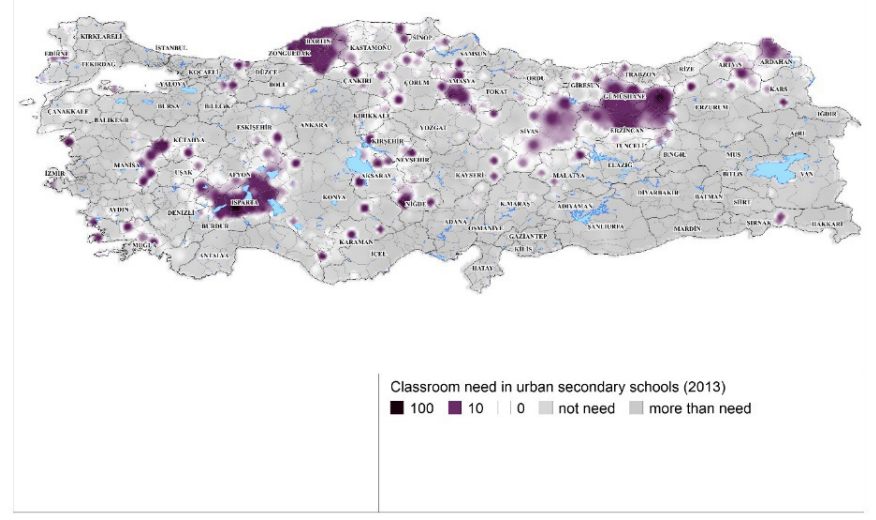

Figure 4: The distribution of classroom need across urban secondary schools (2013)

Nazli Gökçe, Erdoğan Kaya, Semra Günay Aktaş and Yeliz Mert Kantar (2017), Journal of Enterprise Resource Planning Studies, DOI:10.5171/2017.661323 
The map for the distribution of classroom need for secondary schools in urban areas is given in Figure 4. The map in Figure 4 indicates that the number of classrooms in urban secondary schools is not a serious problem in Turkey. However, Isparta, Bartin, and Gumushane should have priority in terms of eliminating the problems regarding classrooms in Secondary schools.

\section{Spatial clustering of distribution of students per class and classroom need in Turkey}

Lastly, in order to further detect local clusters of classroom need, local cluster maps, called as LISA, were developed. From these maps, the following values in Table 1 were filtered. The maps of local cluster (Figure 5) are also used to display Table 1. As seen in Table 1, classroom needs are seen in the east and southeast in Turkey. For urban regions, there are no global clusters.

Table 1: Significant LISA (significant at a 0.05 level)

\begin{tabular}{|l|c|c|c|c|c|c|}
\hline & Moran I & HH & LL & LH & HL & NS \\
\hline $\begin{array}{l}\text { The number of students per } \\
\text { class in rural secondary schools }\end{array}$ & 0.20412 & 63 & 102 & 31 & 12 & 758 \\
\hline $\begin{array}{l}\text { The number of students per } \\
\text { class in urban secondary } \\
\text { schools }\end{array}$ & 0.08849 & 53 & 65 & 28 & 14 & 806 \\
\hline $\begin{array}{l}\text { Classroom need in rural } \\
\text { secondary schools }\end{array}$ & 0.39601 & 80 & 99 & 24 & 14 & 749 \\
\hline $\begin{array}{l}\text { Classroom need in urban } \\
\text { secondary schools }\end{array}$ & 0.36376 & 94 & 55 & 9 & 20 & 788 \\
\hline
\end{tabular}
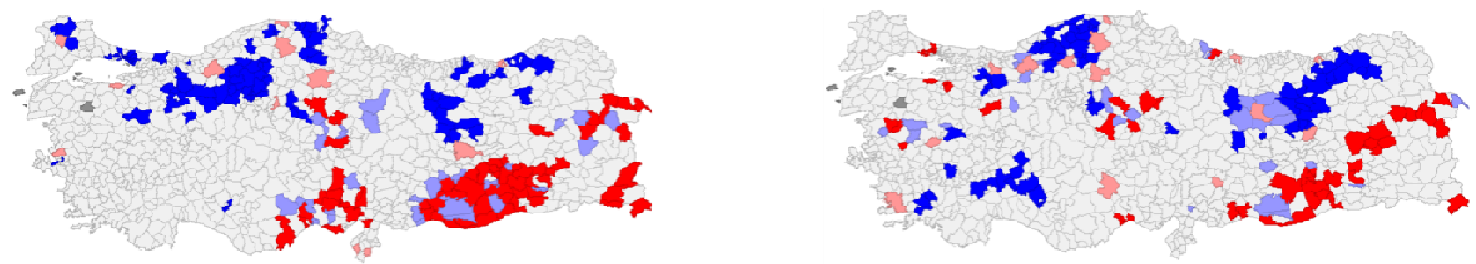

the number of students per class in rural secondary schools the number of students per class in rural secondary schools

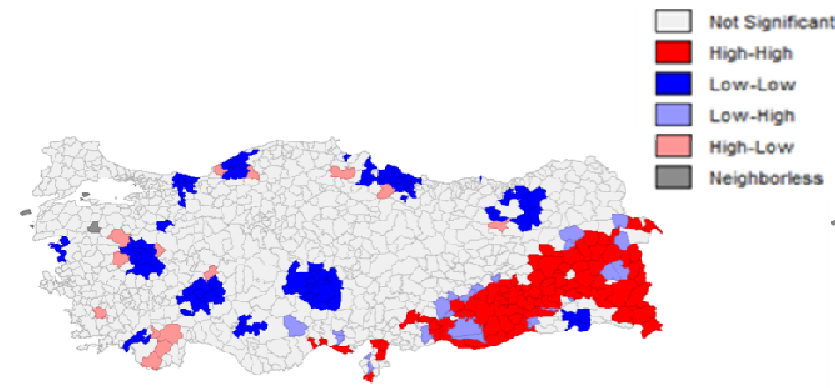

classroom need in rural secondary schools

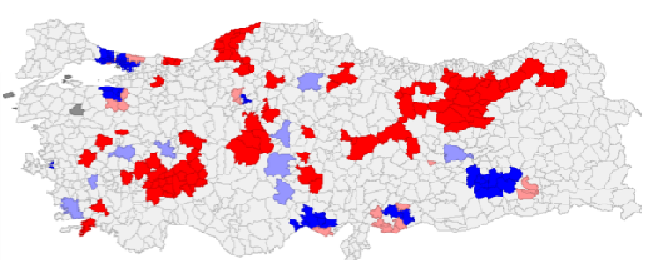

classroom need in urban secondary schools

Figure 5: Moran cluster maps 
Figure 5 shows that the number of students per classroom and the need for classrooms in rural areas are different from urban areas. While metropolitan cities are more prominent in urban areas, areas with high classroom needs in rural areas are clustered in southern and southeastern regions where the rate of population growth is high.

\section{Conclusions}

At the end of the study, it is seen that the change of education system in Turkey $(4+$ $4+4$ ) was no solution for the problem concerning physical substructures of schools, and even this change brought new problems together. Thus, classroom problem, which has been unsolved for years and also emphasized in various studies in Turkey (Ercelebi, 2014; Gedikoglu, 2005; Guven, 2012; Saricay, 2012; Yilmaz and Altinkurt, 2011; Gokce et al. 2017), is still at large. Ercelebi (2014) emphasizes that crowded classes became one of the most important problems when primary schools became eight-year mandatory schools.

Analyses for rural secondary schools show that the number of students per class is very high in Turkey's Southeast and East regions and also throughout some parts of Central Anatolia region such as Ankara, Yozgat, Kayseri, and Konya. Likewise, Adana, a metropolitan city, Mugla, which is a popular-seaside city, and Tekirdag have a problem concerning over-populated classes. In the southeast of Turkey, Sirnak does not have a serious problem as expected. For urban secondary schools, the number of students per class in secondary schools is quite high for metropolitan areas. Also, similar to rural cases, Sirnak, is the province in southeast region of Turkey with no big problem concerning overpopulated classes. On the other hand, for rural secondary schools in the southeast region, except for Sirnak, and for urban secondary schools Isparta, Bartin, and Gumushane should have priority in terms of eliminating the problems regarding classroom need. Finally, the number of students per classroom and the need for classrooms in rural areas are different from urban areas. While metropolitan cities are more prominent in urban areas, areas with high classroom needs in rural areas are clustered in southern and southeastern regions where the rate of population growth is high.

Several other researchers mark that access to education varies dramatically across regions (west-east), gender (boy-girl), and areas (rural-urban) in Turkey (Celikten et al. 2005; Yilmaz and Altinkurt, 2011).

In their research, Yilmaz and Altinkurt (2011) conclude that one of the major issues in the Turkish educational system is the size of classrooms. They underline that over-populated classes cause problems in classroom management, lengthen the time necessary for teachers to get to know their students, lead to a teacher-centered approach, and encourage memorizationbased education, all of which degrade the quality of education. It is well-known that the number of students in a primary school class reaches up to 60 in over-crowded cities such as Istanbul and in eastern provinces where the population grows rapidly. Double-shift education practice in Turkey also indicates that the problem about the number of classrooms is still unresolved, which is included within the $9^{\text {th }}$ development plan as "lessening the number of students in crowded classes and reducing double-shift education."

In another research study, Kastan and Kastan (2016) noted the problems experienced during transiting from eightyear mandatory primary education to primary and secondary school practice as part of gradient approach $(4+4+4)$. Researchers reported that one of the most significant problems that this shift caused was the inefficiencies concerning the physical infrastructure of schools. Schools offering full-time education had to split the day into two shifts as morning and afternoon, pupils in the morning shift have to come to the school at a very early time, and no one including students, parents, and teachers is happy about this change. Besides, school administrators had not been consulted prior to the change, and this led to confusion as to who will be the manager of the new elementary or 
secondary school split from the primary school, which displeased both the administrators and teachers. According to the other research findings, transiting to gradient approach created a vast need for physical spaces, administrators, and assisting personnel. Furthermore, hesitant administrators to choose between elementary and secondary school, elimination of vice-principal position, assignment of administrators to other schools, primary school teachers' anxiety as to which school they would be appointed (elementary or secondary) all diminished the motivation level for both teachers and administrators. For those schools where elementary and secondary education is embodied in one, the administrators have to work for longer hours starting very early in the morning and ending late in the evening because there are two schools but one principal, which results in managerial problems.

In Turkey, physical and technical needs of schools are mostly met by public sources (Tural, 2002). Despite limited and partial improvements as a result of schools' own endeavors, it is not possible to erase the major problems such as classroom need and physical inadequacies without a considerable increase in the allocated budget for national education. Although the rate of MNE within consolidated budget has been increasing since 2002, its proportion to the national income does not follow the same increase pattern, and even it went to the lowest level in 2009 (Yilmaz and Altinkurt, 2011). The inclusion of aims such as "lessening the number of students in crowded classes and reducing doubleshift education" into the $9^{\text {th }}$ developmental plan covering years between 2007-2013 points that this problem is recognized but relevant resources and efforts are not enough, just like in the earlier years.

\section{Acknowledgment}

This study was supported by Anadolu University Scientific Research Projects

Commission under the grant no: 1504E153.

\section{References}

1. Akkalkan, H. (2009), The relationship between the school size and the academic success, school attendance, discipline in Ankara city Cankaya district, Master's Thesis, Ankara University, Ankara.

2. Aydin, A., Sarier, Y. and Uysal, S. (2012), 'The comparative assessment of the results of PISA mathematical literacy in terms of socio-economic and socio-cultural variables,' Education and Science, 37(164), 20-30.

3. Aydiner, A. (2006), In the process of full membership, European Union education policies and their effects on Turkish education system. Master Thesis, Gazi University Institute of Educational Sciences.

4. Basar, H. (1999). Classroom management. Ankara: The Ministry of National Education Publishing.

5. Baytekin C. (2001), 'Contemporary classroom and computer classroom environment,' Sakarya University Journal of Educational Faculty, (2), 120-133.

6. Berberoglu, G., Kalender, I. (2005), 'Investigation of student achievement across years, school types and regions: The SSE and PISA analyses,' Educational Sciences and Practice, 22(4), 21-35.

7. Celikten, M., Sanal, M. and Yeni, Y. (2005), 'Teaching profession and its characteristics,' Erciyes University Journal of Social Sciences Institute, 19 (2), 207-237.

8. Cingi, H., Kadilar, C., and Kocberber, G (2008), 'To examine the opportunities of primary and secondary education in Turkey and to suggest solutions to the determined problems,' TUBITAK Project Report, Project No. 106K077.

9. Dincer, M. A., Kolasin, G. U. (2009), 'Determinants of inequality in student failure in Turkey,' Education Reform Initiative, Istanbul: Sabancı University.

10. Ercelebi, H. (2014), 'To be filled in for eight years of compulsory education,' Pamukkale University Journal of Education, 7 (7), 91-97. 
11. Finn, J. D., Pannozzo, G. M. and Achilles C. M. (2003), "The "why's" of class size: student behavior in small classes,' Review of Educational Research, 73 (3), 321-368.

12. Gedikoglu, T. (2005), 'Turkish education system in the process of European community: problems and solutions,' Mersin University Journal of the Faculty of Education, 1(1), 66-80.

13. Gokce N, Kaya E., Aktas SG, Kantar YM, 'Analysis of Spatial Distribution of the number of students per class in secondary schools for Rural and Urban Areas in Turkey,' Proceedings of the 28th International Business Information Management Association (IBIMA), ISBN: ISBN: 978-0-9860419-8-3, Seville, Spain, 9 - 10 November 2016.

14. Gokce N, Kaya E., Aktas SG, Kantar YM. (2017) 'An Overview of Equal Educational Opportunities in Turkey A Spatial Analysis of Classrooms in Rural and Urban Primary Schools', Journal of Education and Training Studies, 5(1), 67-78.

15. Guclu, M. (2002), 'The problem of crowded classes in primary education and the solution proposal,' Eurasian Journal of Educational Research, 9, 52-58.

16. Isik, H. (2012), 'The physical layout of learning environments. M. Sisman and S. Turan (Eds)'. Classroom Management in (p. 62-75), Ankara: Pegem A Publishing.

17. Karabey, H. (2004). Educational structures: contemporary approaches to planning and designing the schools of the future, principles. Istanbul: Literatür Publishing.

18. Karacali, A. (2006). The evaluation of physical variables which efects classroom management. Gazi University Journal of Kırşehir Education Faculty, 7(1), 145-155.

19. Karakutuk, K., Tunc, B. (2004), 'School size-class size,' Akdeniz University Journal of Education Faculty, 1(1), 9-22.
20. Kastan Y., Kastan Y. (2016), 'Problems experienced in the process of passing from eight- year basic education institutions to $4+4+4$ application in the way of primary and secondary schools and administrative opinions regarding solution: a case study,' International Journal of Social and Educational Sciences, 5(3), 130-155.

21. Ogulmus, S., Ozdemir, S. (1995), 'The impact of class and school size on students,' Education Management, 1(2), 261-271.

22. Sarıcay, N. (2012). Problems of education sector in Turkey, economic dimension of education and solutions. $A R \&$ $G E$ Newsletter, November Issue. Retrieved from

http://www.izmir.org.tr/portals/0/iztogen el/dokumanlar/turkiyede_egitim_sektorun un_sorunlari_14.08.2012\%2010-32-59.pdf

23. Tural, N. K. (2002) Education financing. Ankara: Ani Publishing.

24. Yaman, E. (2006), 'One dimension of the problems of the education system: large classes and classroom management,' Journal of Turkish Educational Sciences, 4(3), 1-16.

25. Yılmaz K., Altınkurt, Y. (2011), 'Prospective teachers' views about the problems of Turkish educational system,' International Journal of Human Sciences, 8(1), 942-973.

26. http://tegm.meb.gov.tr/meb_iys_dosya lar/2012_08/28113239_okuldnmleri.pdf 27. http://mevzuat.meb.gov.tr/html/24.ht $\mathrm{ml}$

28. http://www.resmigazete.gov.tr/eskiler /2012/04/20120411-8.htm

29. http://watchlist.org/wordpress/wpcontent/uploads/Universal-declaration-ofhuman-rights.pdf

30. http://www.unicefturk.org/public/upl oads/files/5db1679769f48db888ea765a0 1dfc8ca9ff67b70.pdf 